\title{
Development Of An Award Winning Volunteer Income Tax Assistance Program: A Case Study
}

William F. Miller, University of Wisconsin, Eau Claire, USA

Brenda L. Thalacker, University of Wisconsin, Eau Claire, USA

\begin{abstract}
The Volunteer Income Tax Assistance (VITA) program, sponsored by the IRS, offers free tax services for individuals with low-to-moderate incomes, the elderly, disabled and/or those who lack English language proficiency. Although established by the IRS in 1969, it is administered by partnering community based volunteer organizations throughout U.S., like universities, schools, religious groups, credit unions or other non-profit organizations. Many VITA sites are sponsored and run by universities through their Accounting departments. The 2012 Internal Revenue Service Advisory Council Public Report indicated that in 2010 only 3\% of qualifying tax returns were prepared at VITA sites, with $62 \%$ of qualifying returns being prepared by paid preparers (IRS, 2012 , p.51). In addition, there are still a large number of individuals who fail to file returns at all often leaving potential tax refunds and credits unclaimed (Lim, DeJohn and Murray, 2012). The purpose of this paper is to share the best practices used at our university to create an award winning VITA program. The specific topics to be addressed are location, layout, operating hours, staffing \& training, process, promotion, electronic filing, other services and things to avoid. These topics are not only what we believe to be the most important in running a successful VITA site but the American Taxation Association 2007 Best Practices Report lists these same topics as well (ATA, 2007). We will conclude the paper with a discussion of our plans for the future growth of the program.
\end{abstract}

Keywords: VITA; Service Learning; Income Tax; IRS

\section{INTRODUCTION}

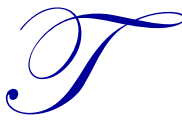

he Volunteer Income Tax Assistance (VITA) program, sponsored by the IRS, offers free tax services for individuals with low-to-moderate incomes, the elderly, disabled and/or those who lack English language proficiency. Although established by the IRS in 1969, it is administered by partnering community based volunteer organizations throughout U.S., like universities, schools, religious groups, credit unions or other non-profit organizations. Many VITA sites are sponsored and run by universities through their Accounting departments.

The 2012 Internal Revenue Service Advisory Council Public Report indicated that in 2010 only 3\% of qualifying tax returns were prepared at VITA sites, with $62 \%$ of qualifying returns being prepared by paid preparers (IRS, 2012, p.51). In addition, there are still a large number of individuals who fail to file returns at all often leaving potential tax refunds and credits unclaimed (Lim, DeJohn and Murray, 2012).

As indicated, there is a real need for the establishment of more VITA sites nationwide, and as we will demonstrate in this article the benefits to be gained more than justify investing the time, energy and resources required to establish such a program. In 1985, our university established a VITA program. While successful it remained small and really languished for years. However, in 2010, under the direction of new leadership, the program soared to new heights winning a regional community service award. 
The purpose of this paper is to share the best practices used at our university to create an award winning VITA program. A brief review of VITA related literature will be followed by general information about our program and a detailed discussion of best practices. The specific topics to be addressed are location, layout, operating hours, staffing \& training, process, promotion, electronic filing, other services and things to avoid. These topics are not only what we believe to be the most important in running a successful VITA site but the American Taxation Association 2007 Best Practices Report lists these same topics as well (ATA, 2007). We will conclude the paper with a discussion of our plans for the future growth of the program.

\section{RELATED LITERATURE}

Recent estimates indicate that approximately two million taxpayers sought help and were assisted from some six thousand VITA sites throughout the U.S. run by more than forty thousand volunteers annually (Price \& Smith, 2008). While a tremendous program, it is still very much in need of additional sponsors, sites and volunteers. Per Lim, DeJohn and Murray(2012), every year families with low-to-moderate incomes lose billions of dollars to paid tax preparers and providers of refund anticipation loans(RAL's). As recently as 2004, more than two thirds of those qualifying to have their returns prepared for free at VITA sites actually paid out more than $\$ 3$ billion dollars in tax preparation fees and another $\$ 1.5$ billion in RAL fees and costs (Lim, DeJohn and Murray, 2012). These numbers do not appear to have improved much since then.

The Earned Income Tax Credit (EITC) is a US governmental bipartisan program to help lift people out of poverty and get them off of welfare. Unlike other credits for qualifying taxpayers, this credit can result in payments back to individuals exceeding the total annual employment tax withholdings. Meaning it can result in a refund in excess of their entire federal income tax liability. An estimated 20 percent of those eligible for EITC do not claim it, amounting to as much as $\$ 1$ billion as unclaimed (IRS, 2012, p.50). While there is disagreement on the dollar value of credits left unclaimed, the percentage of eligible credits filed for does not appear to have improved. Holt (2006) reported that between ten and twenty five percent of EITC credits are never claimed, resulting in some $\$ 4$ billion to $\$ 10$ billion unclaimed each year. There are many individuals who do not participate or who are even aware of its (the EITC's) existence (Lim, Livermore \& Davis, 2009).

For universities who have established VITA programs, the benefits go well beyond the direct benefits received by the community members who seek and receive tax help annually. Very real benefits are received by both the faculty who typically set up and oversee the administration of the program and the student tax preparers themselves (Rama, 2000; Strupeck and Whitten, 2004).

A survey by the American Taxation Association of academics regarding involvement in VITA found participation to be both personally rewarding and valuable to faculty and students (Bauman and Nellen, 2008). Most faculty have service requirements they must meet as part of their job requirements. VITA participation is one way to meet this requirement. In addition, the VITA experience also helps with accreditation requirements in regard to both professional qualifications and with helping the community in which the educational institution operates within. The Campus Compact (2000) called on educational institutions to provide more experiences which link academics with professional and volunteer activities. The institution also realizes an increased connection to the community, contribution to their mission and increased visibility within the community as well (Strupeck and Whitten, 2004). This type of experience also provides faculty an opportunity to develop deeper and more meaningful relationships with their students.

Participation in the VITA program provides benefits to students both intellectually and personally improving their critical thinking skills (Rama, 2000). From an intellectual point of view, program participation provides the student with practical hands on experience putting learned knowledge into practice (Strupeck and Whitten, 2004). From a personal perspective the students gain an appreciation for what they have and how different the lives of others can be.

Per Rama, interacting with this diverse population "can challenge students to reconsider or reaffirm their own perspectives, increase their understanding of other viewpoints and contemplate a wider range of possibilities" (Rama, 2008). Students also see increases in communication skills, interpersonal skills, self-confidence and ethical 
awareness (Carr, 1998). In addition, VITA helps students become more independent, reflective, motivated, flexible, competent, disciplined and confident (Hulsart, 2007). Palmer and Goetz, 2009 found that students who participate in VITA programs are more likely to participate in, develop and organize pro-bono activities post-graduation (Carr, 1998, Palmer and Goetz, 2009).

The literature not only points toward the need for more VITA sites nationwide, but to the many benefits to be derived from participation by the sponsoring institution, faculty and student. The remainder of the article will focus on the best practices to be employed in establishing and managing a VITA program through a detailed discussion of the VITA program we have established. We will then conclude with a look toward the future of this program.

\section{PROGRAM HISTORY}

When the program started in 1985 it was done on a totally volunteer basis. We had a professor who felt very strongly about providing this service who also had extensive tax preparation experience. A couple days a week throughout the tax season she and a hand full of students visited various locations throughout the community and prepared returns: traveling to community centers, nursing homes, libraries and other locations. Each year they would prepare between one and two hundred returns. All of the costs of the program were and continue to be funded through the generosity of the University's Provosts office (whether for equipment or supplies). Each year the Provosts office invests between ten and twenty thousand dollars in the program.

About fifteen years into the program, we started to award one credit of independent study to students for participating. What we found was that in order to attract and keep volunteers, providing credit was helpful. To that end, in 2007 we created a formal one credit elective course which counted toward the students' accounting degree. This was done in conjunction with the university adding a thirty hour service learning graduation requirement. Per McPhail, 2005 (p222), 'service learning is an experiential form of education which facilitates students' involvement in community activities that complement their academic studies'. We agree and we thought that the accounting program should provide its students with a meaningful and relevant way to fulfill their community service requirement.

Our Accounting degree is a comprehensive major comprised of 30 credits of business courses and another thirty credits of specific accounting coursework beyond the introductory level. Back in 2007, the thirty credits of accounting specific coursework included a minimum of seven credits of elective. However, most students end up taking more than that to attain the one hundred fifty credit hours required to be able to sit for the CPA exam. The addition of the VITA elective credit resulted in an increased demand for participation by our students. It also forced us to change from a roaming VITA program, to finding community sponsors and developing fixed VITA site locations. The first fixed locations were established in 2008 resulting in the number of filed returns jumping from under 200 to over 500 .

In 2009 we made the decision to make the VITA class required for all accounting majors, and in the spring of 2012 the VITA course went from one credit to two. To accommodate this increase in required courses, we decreased the number of electives by one credit, thus keeping the total credits for the major at thirty. All of these changes have not only solidified both the accounting departments' and university's commitment to this important program, but resulted in dramatic growth as well.

The number of returns prepared increased to over 600 in 2010 and 700 in 2011, jumping to over 1,000 in 2012. We fully expect to prepare in excess of 1,300 returns in the 2013 filing season as the benefits of all the changes we have made to the program are fully realized. The following sections will discuss what we have found to be the most important areas to consider in designing a VITA program.

\section{LOCATION}

Location is critical to the success of a VITA site. Our experience shows, that you can have a perfectly organized and fully prepared operation, but without customers your efforts will be in vain. Our purpose for 
participating in the VITA program was two-fold; to provide a service to the community and to provide hands on tax preparation experience to our students. We operated three full VITA sites and one facilitated self-service site in 2010 and then dropped down to two full sites and the self-service site for 2011. In 2012 we added a third site back into the mix in addition to the self-service site.

The full time VITA site we dropped in 2011 was at the university (it was replaced in 2012 with an additional off campus site). Even though a college might seem to have been an ideal location since there are a lot of low income taxpayers on campus (aka students) this was our least used site. The hours were limited and did not necessarily coincide with a lunch break or other breaks during which students or University staff could have their tax returns prepared. Finally, because of parking limitations at the University we did not have any taxpayers from the community come in for tax preparation. While the University is on the local bus route, unless you are familiar with the campus, the thought of walking around the campus can be intimidating. Our target population simply was not comfortable coming to the University's VITA site. As a result, the students who had signed up to prepare taxes at the University site were not gaining any hands-on tax preparation experience.

In addition to our on campus site, we also run three full service off-campus locations as well. Initially we operated these off site locations just three afternoons per week. However, it quickly became apparent that we could reach many more potential clients by expanding our operations. We now have one full service VITA site open four days a week. The primary reason for the success of these three sites was location and their proximity to public transportation (all were on the local bus route).

The three off-campus sites and sponsors have proven to be great partners. We used the experience and knowledge we gained from the first two sites in selecting and setting up the third site we added in 2012. In order to fully appreciate the details regarding the third site, we do not specifically address it until the conclusion of the paper.

One of our original off-site hosts is a non-profit agency. Their mission is to alleviate poverty related conditions and provide opportunities which enable people to advance economically and socially. The VITA program provides a service to the same individuals as the sponsor: they host the VITA site one afternoon per week from February $1^{\text {st }}$ through April $15^{\text {th }}$. The second location is hosted at one of the branches of a Credit Union. The credit union has over 140,000 members from communities in both multiple states. They are an active partner in the community. Each year, the credit union makes financial and in-kind contributions and donations of over $\$ 125,000$ to a number of eligible organizations. VITA is an extension of the many services they already provide to the community: hosting one VITA site two afternoons per week from February $1^{\text {st }}$ through April $15^{\text {th }}$.

Both of these locations are easy to get to, and were known to the potential clients, since the businesses already served many of the clients we hoped to attract. However, we learned that there is much more than location involved in creating a successful VITA program. One of the two offsite locations ended up being much easier to run and more successful than the other. While both were good solid sites preparing many returns, one was clearly better.

\section{OPERATIONAL LAYOUT}

We learned that the layout of the operation can also help maximize the performance of the operation. At one of these locations, we had a large room which we were able to break up into separate tax preparation areas, and still retain client privacy. We also had a waiting room at this location, separating clients from the preparation staff. Because the students' did not know how many taxpayers were waiting they were able to focus on the current taxpayer rather than worrying about how many people were waiting.

Comparatively, the second location was very small. A small conference room was used to prepare the tax returns and there wasn't a separate waiting room. This location was a credit union and our clientele had to wait in the lobby. The lobby was so small we had to set up a folding chair and table for the greeter to sit at with the sign-in sheets and intake forms. The lobby had limited seating and sharing the space with the credit union was very disruptive for both the credit union's members and employees. Even though there were seven to eight tax preparers on duty, this site only provided enough room for three tax returns being prepared at a time. Another issue at this 
location was the speed of the internet service. Because this site was a credit union, we were not able to use their internet due to security issues. We set up a separate wireless connection which ended up being very slow. This resulted in quite a bit of time being wasted.

As a result of these issues, we met with the credit union decision makers and discussed possible solutions. They were very accommodating and proposed a different site which overcame all of the previous site's limitations. This change in location enabled us to prepare approximately 100 more returns than we had prepared in the previous year.

The replacement site was at another branch of the credit union (the location was also known to the community and our potential clients), on the bus route, and clientele were comfortable coming to this location. This new location provided us with a large room for tax preparation, a waiting room and the credit union was able to set up and provide us with our own high-speed internet access. The one downside was that these rooms were in the basement. However, this credit union had extra capacity in their office area and also provided us with a street-level office for taxpayers who could not maneuver down the stairs. An additional benefit by having VITA at a different branch of the credit union was their lobby area. This branch's lobby area was more spacious and had more seating than the first site had.

\section{OPERATING HOURS}

Along with finding a different location at the credit union, we needed to expand our hours to provide more students with VITA experience. The management at the new location of the credit union was willing to host the VITA sites two afternoons per week rather than the one afternoon per week that the other branch of the credit union had provided. This turned out to be beneficial to operate the same site location on consecutive afternoons. The combination of having a larger more efficiently run site and the ability to operate the site more days per week, allowed us to service many more clients than we would have otherwise. We cannot be more pleased with the relationship we have established with the credit union.

We do have one limitation with our full service sites that we have not been able to overcome: we can only have one location open on any given day. In addition, our hours of operation are also limited to the normal business hours that the site business hosts are typically open for business. The first of these limitations is self-imposed. We think that having the faculty administrator at each of the sites while they are open is required. She obviously can't be in two places at once. However, we did try something new in 2012 with our facilitated self-service site to get around this limitation.

\section{SELF SERVICE SITE}

Since we historically had limited success on campus, we decided to try setting up a facilitated selfassistance site (FSA) at the University for 2011. FSA sites provide people with access to computers and the software to prepare their tax returns themselves and file them for free. The FSA sites are set up for individuals who have some computer skills, have a simple return and may need little or no help in preparing their tax return. Since most of the University's population is comfortable working with computers we decided to make this opportunity available to them. At this site, we had a student with experience from the previous year's VITA site available for assistance.

The student was able to provide software and tax code assistance. Although the IRS doesn't require the FSA site coordinator to have the IRS certification through the Advanced Level and the Site Coordinator certification, we did require our FSA coordinator to have those levels of certifications. The faculty administrator was available via phone for any questions the FSA site coordinator had. The FSA site hours coincided with our VITA site hours. Therefore, by having a student as the FSA site coordinator this allowed our faculty administrator to be on site at the VITA locations and be available to the FSA site coordinator at the same time. Since our FSA site coordinator had passed through the Advanced level of certifications she was very knowledgeable and did not need to make any calls to the faculty administrator about any tax preparation questions. 


\section{STAFFING AND TRAINING}

The VITA requirement is packaged as a high-impact learning experience which is considered extremely valuable. All of our graduates are required to take this two credit course. It is comprised of both classroom learning and onsite tax preparation experience. All of our VITA sites and the FSA site are staffed by students. Our students are required to sign up for VITA as a two credit course. The VITA two credits are earned through a combination of classroom work and tax preparation work at the VITA sites.

Each student must be certified by the Internal Revenue Service. The IRS's certification program called 'Link and Learn Taxes' is available online at www.irs.gov. All students must be certified through the Advanced level and pass the certification in foreign student taxes, prior to working at the VITA site. This certification takes each student approximately forty hours to complete. Because of the semester's timing, all students are expected to get their certification completed during the semester break between the Fall and Spring semesters.

Once the semester begins we do review some key topics such as Filing Status, Dependency guidelines and Earned Income Credit in class. We spend a total of eight hours in class over two weeks prior to opening the VITA sites for tax season. The remaining in-class training focuses on state taxes, VITA procedures and the use of the IRS's TaxWise software. We also place emphasis on the Homestead Credit as well. A pre-requisite for our students to be in the VITA program is the completion of a University income tax course. However, this course does not address state income taxes. Therefore, we spend a considerable amount of time in class covering our states' tax filing requirements.

Any time we prepare taxes for testing purposes in class, including the certification testing, 'TaxWise Online' demo is used. This familiarizes the students with the IRS tax preparation software. It is set up for Federal Income training purposes only. Therefore, we cannot practice preparing any state tax returns until we have access to the live TaxWise Online software.

The remaining class time is then spent on VITA procedures. During the last class period before we start preparing tax returns we meet at the VITA site where the specific student will be working. This often times is the first time the student has been at a business in this sort of capacity. Besides meeting the employees at the sponsoring site and getting acclimated to the space, administrative items such as computer log-in information, copy machine location and access codes (if needed), printer locations, shredder location, and sign in procedures for taxpayers are covered. We run through the entire process of what happens from the moment a client walks through the door until they leave (hopefully with a completed tax return).

One of the most important topics we discuss is treating everyone with respect along with using appropriate communications with the taxpayers. Most students have never asked anyone for tax information before. Sometimes they ask for the information and it is obvious the taxpayer has no idea what they have been asked for. This is when the student must be able to explain what they are asking for. Having the ability to explain tax information to the taxpayer enhances both the students' confidence and understanding of taxes. We have found that the more time we spend preparing the students, the smoother the entire process goes.

\section{OPERATIONAL PROCESS}

All of the VITA sites are set up on a first-come, first- serve basis. The taxpayers are allowed to come in to the hosting location when that business opens for the day. The taxpayer may sign up to have their tax return done that day. In the afternoon, when we start preparing taxes we prepare the returns in the same order the taxpayer's signed in. If the taxpayer isn't there, we skip over their name and call the next person. When the taxpayer shows up, we will prepare their taxes when the next available preparer is ready.

We are able to prepare taxes for eleven or twelve taxpayers simultaneously (depending on the number of students who are in a particular section of the course). At each of the sites, we pre-number the sign-in sheets with the number of tax returns estimated that we can prepare on any given day. At the beginning of the tax season, we cannot prepare as many tax returns as we are able to prepare later on in the tax season. The students' throughput 
improves greatly with experience. As the season progresses, the students become more familiar with the tax software along with handling various types of tax information.

We make a commitment to the taxpayers who have signed up on the pre-numbered sheets that we will prepare their return that day. After all of the pre- assigned numbers are signed up for, additional taxpayers are allowed to sign up knowing that we may not be able to get to them that day. While this may create stress for the taxpayer, it relieves stress for the tax preparers. They do not feel pressured to rush through any tax return.

When a taxpayer comes into the business, they are greeted by a host site employee. A sign-up sheet is available for the taxpayer to sign in. Once signed in, the person is required to fill out an IRS provided intake sheet. This insures that they have all the data they will need for us to be able to actually prepare their return. Instructions on what to do are displayed by the sign-up and the intake sheets. A listing of required documents needed by the taxpayer is also located by the sign-up sheet. If the taxpayer needs help filling out the intake sheet, the faculty administrator or a tax preparer will assist them.

Typically the taxpayer will ask questions if they discover they do not have all of the documents needed. The taxpayer is usually able to complete their intake sheet while they are waiting for a tax preparer to become available. Once the intake sheet is completed, it is used by the tax preparer as an information source in completing the taxpayer's return. This intake sheet is required by the IRS. The student who reviews the intake sheet and supporting documents also prepares the tax return. Once the return is completed, the student lets the faculty administrator (who functions as the reviewer), know the return is ready for a review. In reviewing their return, the intake sheet and completed online return is used. We do not print any tax return until the reviewer has reviewed the tax return.

From the moment the student starts working with the taxpayer, they are encouraged to make the client feel at ease. The student always introduces themselves to the taxpayer. Depending on the student and the taxpayer, the initial introductions can take a while since the taxpayer may ask questions about the student and vice versa. The more at ease the student tax preparer is with the taxpayer, the more willing the tax payer is to openly share information (rather than the student having to specifically ask for the information). This greatly speeds up the preparation process and improves the overall satisfaction level of both the preparer and the taxpayer.

At the beginning of the tax season all of the tax returns are reviewed by the faculty administrator. This can create a potential bottleneck in the process. However, each student takes this time to review their input and check off the boxes on each input document so the reviewer will know that they have done a review of the input documents. If there are two students who are both waiting for a review, the faculty administrator (reviewer) may ask them to review each other's work. However, the reviewer still reviews the return. The faculty administrator does the reviews because few students have the required previous tax preparation experience to be qualified to review.

\section{PROMOTION}

Our VITA sites have been promoted by both the host sites and the University. Each host site has a newsletter in which the VITA information is included. These newsletters reach a large number of community members. The host sites post the VITA hours and information on their businesses' website also. The University sends information to the local newspapers along with posting information on their website as well. At each location, posters are placed in prominent locations. This form of marketing appears to have worked quite well, as we are not lacking for customers at any of our sites.

\section{ELECTRONIC FILING}

The VITA program is sponsored by the IRS. Because the program is sponsored by the IRS the software is selected by the IRS and each VITA site is given the software to use. The software can only be accessed online. The online access is great especially since there generally tends to be updates to most tax software throughout the tax season. With the online access, the updates are done by the tax software publisher rather than each VITA site downloading the tax updates on each computer. 
Almost all of the tax returns can be filed electronically. VITA sites are not responsible for any electronic filing fees. The only returns that cannot be filed electronically are the same returns that any other tax practitioner cannot file electronically; for example, returns including the first-time home-owner's credit, or a tax return where the taxpayer needs to submit a divorce decree to prove he/she may take a dependent.

Electronically filed returns are done in batches at the end of the day, after the customers have long since gone home. This is unfortunate, because some returns are rejected by the IRS and require more or different information before they will be processed by them. If a return is rejected, we have to follow-up with the taxpayer within twenty four to thirty six hours after we have received the rejection notice. For the non-electronically filed returns we print them out and send them home with the client to be mailed by them.

\section{ADDITIONAL SERVICES}

Besides preparing taxes for low-income individuals we have two additional tax preparation sessions when we prepare tax returns for the foreign students who attend our university. These sessions are very popular with those students because most tax practitioners do not want to prepare those types of returns. During these tax preparation sessions only foreign student returns are prepared. We have a foreign student template set up in the software. For these sessions, this template is set up as the default template. All of these returns must be mailed to the IRS therefore we give each foreign student a pre-addressed envelope for them to use when they send in the return. The student preparers are required by the IRS to take the foreign student certification test before they can prepare these returns.

\section{ADVICE FROM THE ADMINSTRATOR}

Through the ten plus years of managing VITA sites the administrator tried many different approaches to enhance the learning experiences for the student preparers and to maintain a well-run, efficient VITA site. Some things that have not worked at the VITA sites she managed surrounded the tax payer waiting list, the actual tax return assembly process and accepting that some returns cannot be prepared by VITA sites. Originally, she had allowed an unlimited amount of taxpayers to put their name on the waiting list. Some of the taxpayers thought that by having their name on the list they were guaranteed to have their taxes done that day. As mentioned previously we now use a pre-numbering system to avoid having disgruntled customers and to take the pressure off of the student preparers. While we do allow people to sign up beyond the limit, they do so knowing that they may have to come back a different day.

Assembling the return can be confusing to tax preparers who have never had any involvement in preparing anyone else's return or even their own return before. For the first couple of weeks the administrator has a volunteer help with assembling the returns. That volunteer is trained on that task only and they are expected to train the students on how to eventually assemble the returns they file. By assembling the return, we are referring to printing the taxpayer's return, pulling the Form 8863, getting their signature, pulling the W-2s and other documents with withholding taxes, telling the taxpayer their refund/amount owed and if a refund when to expect their refund. Using a student dedicated to assembly provides the student preparers time to get accustomed to the entire return preparation process.

Finally, it is important to be realistic and recognize that a VITA site is not the equivalent to a professional for profit tax filing service. If the tax preparers are unable to prepare a tax return, either because it is outside of their level of certification or because it doesn't meet the VITA guidelines, the customer must be turned away. The IRS has established VITA site guidelines on the filing of returns that must be followed. The site administrator has had site visits from the IRS and states that the last thing you want to happen to your VITA site is for it to be closed. If closed, your customers will either have to find another VITA site or not receive the free tax preparation assistance. Following the VITA guidelines is critical. 


\section{CONCLUSION AND OPPORTUNITIES FOR GROWTH}

We are very proud of the VITA program that we have developed and believe the benefits we have gained more than justify investing the time, energy and resources required to establish and maintain it. Besides learning how to prepare tax returns and communicate with all types of people, the students gain critical thinking skills and confidence. This confidence will help the students in their future accounting careers. The students also gain an appreciation for what they have, as well as the importance of giving back to the community. In addition, the learning that results from hands-on tax preparation really solidifies the knowledge gained in the students' first tax class. We get comments from the firms that recruit our students in regard to how pleased they are that our students have this experience.

Faculty also benefit from participation. Not only does participation result in keeping professionally qualified, it provides faculty participants a real sense of accomplishment. Faculty get to see the students mature into seasoned tax professionals and know that the work that is being done is invaluable to the community.

Finally the university itself gets recognition for the good works it sponsors in the community. The VITA program provides a wonderful bridge between the university and the communities it serves. Should your university have community service requirements for students and faculty, this program provides another avenue for the successful completion of those requirements.

As our accounting program continues to grow, we will need to find ways to grow the VITA program as well. The alternatives to consider include expanded operating hours, additional sites and possibly adding a second administrator to help manage the program (or reduce or eliminate the teaching load of the administrator). As previously mentioned, in 2012 we added a third off-campus location and now have a full service site open four days a week. We were able to use what we had learned over the years in selecting the new site in 2012.

While we had the opportunity to either add another day at the credit union site, or even open another site at a different branch of the credit union, we chose to add both a full third VITA site, and a third sponsoring organization as well. We were very appreciative of all the work and resources that our sponsoring organizations do for us, we thought it was important to maintain our identity as the site operators. So the third sponsor we chose was not a business, but a small city. Having a third sponsor also minimized the risk to the operation should one of our sponsors ever choose to employ their resources elsewhere.

We wanted a unique location which would be available to taxpayers who were unable to come to either of the two other locations. Our city, while quite large, is surrounded by quite a few communities in close proximity. Our current locations service downtown and the southern part of our city. Therefore, we concentrated our search to the North, East and West. As previously discussed, location is extremely important to the success of the operation. Not only does the site need to be close to your potential clients, easy to get to, but preferably a site they are comfortable walking into.

While we were able to identify a number of potential sites, we ended up selecting a city just ten minutes west of the campus, making it easy for our student workers to get to the location. The City's community room has all of the amenities we think are important to make a site successful. The community room is located in the same building as the City Hall and the Public Library. It is not only on a bus line, known to our potential clients, but is a building everyone is very comfortable coming to.

The City readily agreed to sponsor our third full VITA Site. The city employees were extremely excited and welcoming about this opportunity for a VITA site in their community. We were excited to be reaching out to even more taxpayers than before and providing all of our students the opportunity for public service and gaining professional tax preparation experience. Overall, the warm reception we've received from our new sponsor has been the same welcoming reception we received from our two other host sites. This too can make a huge difference in the success of a program. Our first year of operation at this new facility was very successful, with us preparing under 200 returns just one day a week at this new location. We are looking forward to many more years of VITA participation. 
In conclusion, we have found that the most important areas in successfully developing a VITA program are location, operational layout, operating hours, staffing and training, process and program promotion. We hope that the sharing of our experience might help others whose existing VITA programs are struggling, or who are considering developing a program of their own.

\section{AUTHOR INFORMATION}

William Miller, Ed.D., CPA, is an Assistant Professor of Accounting at the University of Wisconsin - Eau Claire. Dr. Miller has extensive industry experience ranging from start-up companies to fortune 500 companies and investment banking. His academic research interests include accounting ethics and issues related to IFRS. His main areas of teaching include accounting ethics and financial accounting. E-mail: millerwf@uwec.edu (Corresponding author)

Brenda Thalacker, Ed.S., CPA, is the VITA Program Administrator and Accounting Lecturer at the University of Wisconsin - Eau Claire. Ms. Thalacker has extensive professional experience in tax preparation and many years of teaching undergraduates introductory accounting, introductory tax and advanced tax.

\section{REFERENCES}

1. ATA. (2007). American Taxation Association VITA Best Practices Report: Pro Bono Tax Services Task Force 2007. http://aaahq.org/ata/public-interest/reports/vita-best-practices-report_oct07.pdf. Retrieved $12 / 1 / 2012$.

2. Bauman, C., \& Nellen, A. (2008.) Academic-based vita programs. Tax Adviser, 39(8), 531-534.

3. Buchanan, A., Baldwin, S., \& Rudisill, M. (2002). Service learning as scholarship in teacher education. Educational Researcher, 31(8), 30-36.

4. Campus Compact (2000) Presidents' Fourth of July Declaration on the Civic Responsibility of Higher Education, Providence, RI. , http://www.compact.org/resources-for-presidents/presidents-declaration-onthe-civic-responsibility-of-higher-education/, Retrieved 12/20/2012.

5. Carr, J. (1998). Service-learning in accounting: A role for Vita tax programs. In D. V. Rama (Ed,), Learning by Doing: Concepts and Models for Service-Learning in Accounting (pp.101-116). Washington, DC: American Association of Higher Education.

6. $\quad$ Colbert, T. V. (2011). Leadership Begins by Showing Up. Student Lawyer, 39(8), 40.

7. Drougas, A., \& Harrington, S. (2011). Using vita service learning experiences to teach hypothesis testing and p-value analysis. Journal of Instructional Pedagogies, 6, 1-15.

8. Holt, S. (2006). The Earned Income Tax Credit at age 30: What we know. Washington, DC: Brookings Institute.

9. Hulsart, R. W. (2007). Small Numbers, Large Returns: College Students Helping Community Members Prepare Income Tax Returns. College Teaching, 55(2), 48-50.

10. IRS. (2012). Internal Revenue Service Advisory Council 2012 Public Report. http://www.irs.gov/PUP/taxpros/providers/IRSACFinalReport2012.pdf. Retrieved 12/19/2012.

11. Long, B. (2007). Vita, the MTC and the modern accounting curriculum (part ii). Tax Adviser, 38(11), 692694.

12. Lemoine, K. (2008). Tax time is almost here: Sign up now for a vita program. Student Lawyer, 36(7), 45.

13. Lim, Y., DeJohn, T., \& Murray, D. (2012). Free tax assistance and the earned income tax credit: Vital resources for social workers and low-income families. Social Work, 57(2), 175-184.

14. Lim, Y., Livermore, M., \& Davis. B.C. (2009). Knowledge of the Earned Income Tax Credit and financial behaviors among low- and moderate-income consumers. Journal of Consumer Education, 26, 1-12.

15. Madden, J. (2003). Getting Money to the Workers. Policy and Practice, September 2003.

16. Mcphail, K. (2005). Care in the community: Professional ethics and the paradox of pro bono. Accounting Education, 14(2), 213-227.

17. Meinhard, A., \& Brown, S. (2010). School Community Service Programs: Essential Features for Success. Journal Of Nonprofit \& Public Sector Marketing, 22(3), 216-230. doi:10.1080/10495142.2010.483273.

18. Miller, J., \& Weiss, C. (2008). The importance of CPAs supporting VITA: One CPA's experience. Tax Adviser, 39(7), 461-462. 
19. Nellen, A., Bauman, C., Nichols, N., Anderson, S., \& Outslay, E. (2005). Pro--bono tax services: The role of tax academic and students. Tax Adviser, 36(8), 500-504.

20. Palmer, L., Goetz, J., \& Chatterjee, S. (2009). Expanding financial education and planning opportunities through service-learning. Financial Services Review, 18(3), 157-175.

21. Price, D. W., Smith, D. L. (2008). Income tax service learning opportunities: A look at alternative models. Global Perspectives in Accounting Education, 5, 43-53.

22. Rama, D. Ravenscroft, S., Wolcott, S., \& Zlotkowski, E. (2000). Service-learning outcomes: Guidelines for educators and researchers. Issues in Accounting Education, 15(4), 657-692.

23. Strupeck, C. (2004). Accounting service-learning experiences and the IRS volunteer income tax assistance programme: A teaching note. Accounting Education, 13(1), 101-112. 
NOTES 